
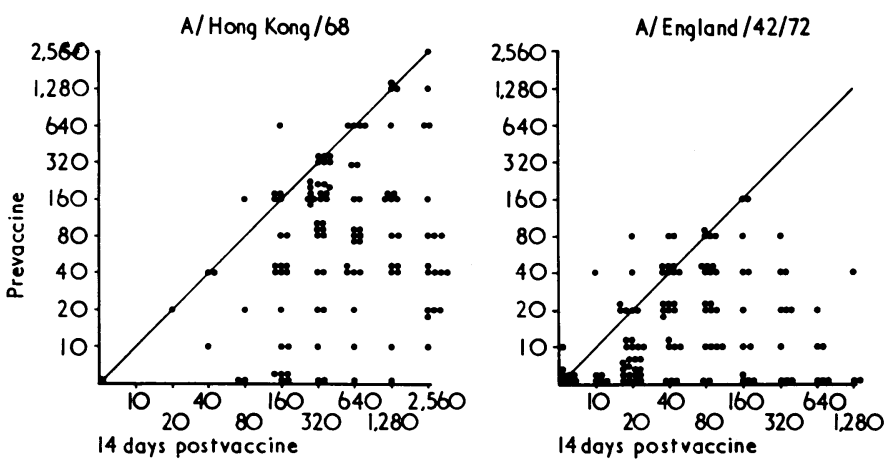

FIG. 2-Haemagglutination inhibition response in 118 people given inactivated A/Hong Kong/68 vaccine.

These results can be compared with some obtained with sera taken during a vaccine study done in the U.S.A. in 1968 before the first $\mathbf{A} /$ Hong Kong/68 epidemic had occurred. In this study A/Hong Kong/68 vaccine was given to 20 people, $90 \%$ of whom produced antibody titres of $\geqslant 1 / 40$ to the homologous virus. However, when the postvaccine sera were tested with $\mathrm{A} /$ Queensland/6/72 virus, which is similar to the A/England/ $42 / 72$ variant, only $10 \%$ had titres of $\geqslant 1 / 40$

\section{Discussion}

Studies of the impact of the A/Hong Kong/68 virus on the population of Britain showed (Miller et al., 1971) that after the first two years of epidemics only about $30 \%$ of the population were without antibody. During the following two years the same virus was detected to a small extent during the winter of 1970-1 and rather more extensively during the winter of 1971-2. The frequency of antibody after these four winters was examined in sera taken during the summer of 1972, and it was found that by this time with all ages averaged only $17^{\circ},{ }^{\prime}$ were without demonstrable antibody. The results were broadly similar to those found with sera taken in September 1972 in the U.S.A. With the appearance of the variant typified by $A /$ England/42/72 it was clearly of importance to see what effect this degree of antigenic difference would have on the antibody pattern.

The results in this study were analysed to separate the sera with titres of $1 / 40$ or more from the rest. The reason for this was based on evidence gathered in other studies (Miller et al., 1972) that this level of antibody appeared to confer protection against infection. When this was done it was found that whereas $73 \%$ of the sera had antibody at $\geqslant 1 / 40$ to the $\mathrm{A} / \mathrm{Hong} \mathrm{Kong} / 68$ virus an average of only $37^{\circ}, \mathrm{o}$ had antibody at these titres to the variant $\mathrm{A} /$ England $/ 42 / 72$, and the proportion in certain selected groups was actually considerably lower. For example, in a small collection of sera from students in England only $11 \%$ had antibody at titres of $\geqslant 1 / 40$, and a similar low proportion $(10 \%)$ was found in a small number of sera from adults in the U.S.A. Thus it became clear that if the variant spread during the winter of 1972-3 the population would be largely unprotected against it. It was therefore of interest to determine whether conventional inactivated influenza vaccines containing A/Hong Kong/68 virus would stimulate antibody to the variant $\mathrm{A} /$ England/42/72.

Results with sera from a small study done in the U.S.A. before the A/Hong Kong/ 68 virus appeared suggested that the response to $\mathrm{A} / \mathrm{Hong} \mathrm{Kong} / 68$ vaccine would induce only a minimal response to the $A /$ England $/ 42 / 72$ virus. However, the vaccine study reported here showed that although the effect was not as good as with the homologous virus, since all but two sera $(98 \%)$ developed antibody to $\mathrm{A} /$ Hong Kong $/ 68$, the response was nevertheless much greater than had been expected, with the proportion of those with antibody to the A/England/42/72 variant increasing from $25^{\circ}{ }_{\circ}$ to $63 \%$ by 14 days after the vaccination. This greatly improved cross-reacting response presumably reflects the presence of a high incidence of considerable titres of $\mathrm{A} / \mathrm{Hong} \mathrm{Kong} / 68$ antibody. These findings suggest that this vaccine will not be ineffective in boosting antibody to the A / England / 42/72 variant and should be used to protect those particularly at risk until influenza vaccines containing the appropriate strain become available. In order to provide potential vaccine strains of $\mathrm{A} /$ England/42/72 virus which produce high virus yields and therefore enhance the rate at which vaccine can be produced, high-yielding recombinant strains (Kilbourne, 1969; McCahon and Schild, 1971) antigenically identical to A/England/42/72 have been produced, and their properties will be described elsewhere (Schild, 1972).

We should like to thank Mr. P. Cunningham for his excellent technical help. The directors of the public health laboratories who sent us sera for testing were: Dr. H. R. Cayton, Bristol; Dr. G. R. E. Naylor, Cambridge; Dr. G. C. Turner, Liverpool; Dr. P. R. Mortimer, Teesside; and Dr. D. J. H. Payne, Portsmouth.

\section{References}

Kilbourne, E. D. (1969). Bulletin of the World Health Organization, 41, 643. McCahon, D., and Schild, G. C. (1971). Fournal of General Virology, 12, 207. Miller, D. L., Pereira, M. S., and Clarke, M. (1971). British Medical fournal, 1,475 .

Miller, D. L., Read, D., Diamond, J., Peveira M. S., and Chakraverty, P. (1972). To be published.

Pereira, H. G., Pereira, M. S., and Law, V. G. (1964). Bulletin of the World Health Organization, 31, 129.

Schild, G. C. (1972). To be published.

Schild, G. C., Pereira, M. S., Chakraverty, P., Coleman, M. T., and Dowdle, W. R. (1972). To be published

\title{
Method of Breech Management Incorporating Use of Fetal Blood Sampling
}

\section{B. W. ELIOT, J. G. HILL}

British Medical fournal, 1972, 4, 703-706

\section{Summary}

We have developed a method of breech management based on the use of fetal blood sampling. Twenty-five cases were studied throughout labour, and fetal blood samples taken throughout the first and second stages.

\footnotetext{
Department of Obstetrics, Pembury Hospital, Tunbridge Wells, Kent

B. W. ELIOT, M.B., M.R.C.o.G., Registrar

J. G. HILL, F.R.C.S., M.R.C.o.G., Consultant
}

These showed that the Apgar score at one minute correlated closely with the fetal pH just before delivery. We believe that cord compression is an important variable factor which can be assessed only by fetal blood sampling. If this shows that fetal anoxia is becoming severe then immediate delivery is mandatory.

\section{Introduction}

Over the years there has been considerable diversity of opinion regarding the main cause of death in the baby delivered as a 
breech. In the early part of this century it was thought that the usual cause of fetal death in breech delivery was asphyxia, produced by pressure on the umbilical cord during the delivery of the shoulders and the after-coming head. In consequence, it was generally thought that to secure a live baby the aftercoming head had to be extracted as speedily as possible, and certainly within five minutes of the appearance of the umbilicus at the vulva. However, when Eardley Holland (1920) showed that intracranial haemorrhage and dural tears were found in $75 \%$ of all stillborn breech babies, the pendulum swung in the opposite direction, and there was a profound alteration in the teaching regarding the technique of breech delivery. Stress was no longer put on speed, rather on gentleness and deliberationespecially during delivery of the after-coming head. It must be remembered, of course, that in those days extension of the legs was regarded as a complication, and it was common practice to bring down one or both legs before the second stage was reached. Consequently, many of the fatal cases of haemorrhage must have resulted from extraction of the head through the incompletely dilated cervix (C. K. Vartan, personal communication, 1972). Nevertheless, there was support (Gibberd, 1931) for Eardley Holland's view that three-quarters of the intranatal mortality in breech delivery could be accounted for by haemorrhage, and since then this has been widely accepted in British obstetric teaching. As a result fetal asphyxia, which was previously thought to be the main danger, has now been accorded a much diminished role. The risk of asphyxia has continued to worry many obstetricians, however, and in an effort to avoid damaging delay modified breech extraction has been advocated both in Britain (Hay, 1959) and in the United States (Tompkins, 1943; Dieckmann, 1946). The consensus of opinion among British obstetricians, however, remains firmly in favour of a more conservative approach to the assisted type of breech delivery.

In the analysis of all breech delivery statistics the overriding emphasis has always been on the mortality rate. In order to gauge the success of any particular method of breech delivery it is necessary to look beyond the question of mere survival and assess the quality of life in later years-in other words, the mental capacity of the individual. Although it is known that prolonged asphyxia damages brain cells, modern textbooks show a surprising complacency towards moderate asphyxia. Chassar Moir (1971) stated that it is surprising how long the fetus will live without a supply of oxygen. He quoted an instance when a live fetus was delivered by postmortem caesarean section 15 minutes after the mother's death, and concludes that the anoxia suffered by the fetus during breech delivery is seldom of sufficient duration to become dangerous. Donald (1969a) advised that not more than 10 minutes should elapse from the time the head has entered the pelvis until the child is in a position to breathe. Gibberd (1955) said that it is not possible to define the length of time that may elapse between compression of the cord and the death of the fetus from asphyxia, but there is good reason to believe that the fetus can generally survive at least 10 minutes of complete asphyxia, and in many cases the time limit may be much greater. Again, Gibberd's emphasis is on survival, but it must surely seem that such prolonged periods of anoxia must have some effect on the fetal brain. Donald (1969b) pointed out that the immediate effects of asphyxia are those of venous engorgement, especially in the brain, so that compression of the fetal skull, by dragging the apex of the tentorium upwards, may sufficiently restrict venous flow to raise back pressure to the point at which smaller tributary vessels rupture, even though the tentorium is not actually torn. It is known that complete anoxia injures the capillary endothelial cells very promptly, and within a few minutes their permeability rises sharply (Payling Wright, 1960). It therefore seems logical to assume that a degree of asphyxia which is not sufficient to cause death may, nevertheless, in the presence of minor trauma, precipitate a slight and non-fatal cerebral haemorrhage. It seems equally obvious that such periods of asphyxia must have an adverse long-term effect on the mental capacity of the baby.
With these thoughts in mind, we set about devising a method of recognizing early fetal anoxia during breech delivery.

\section{Material and Methods}

Before it was possible to formulate a rational method of breech management incorporating fetal blood sampling, it was necessary to elucidate the basic physiological changes in the $\mathrm{pH}$ during the second stage of labour. We therefore undertook a pilot study of 25 cases in which the changes in the $\mathrm{pH}$ were evaluated.

In our antenatal clinic we carry out external version at or about the 34th week in primigravidae and slightly later in multigravidae. We accept Vartan's (1945) opinion that extended legs and scanty liquor are the main causes of failed version, and so if the legs are found to be in the extended position and there is very little liquor it is considered that version is not feasible. If the breech presentation persists clinical assessment of the pelvis is carried out at a later date, and at the same time a single lateral pelvimetry film is taken. If the pelvis is found to be satisfactory labour is induced between 38 and 39 weeks. Any other obstetric abnormality such as multiple pregnancy, preeclampsia, or a small-for-dates baby has been excluded from the series. Immediately after the membranes are ruptured, an oxytocin infusion is set up. The patient is then carefully observed, and from the onset of contractions the fetus is monitored continuously by the cardiotocograph. Towards the end of the first stage a fetal blood sample is taken, and provided this is within normal limits and progress is satisfactory, the labour is allowed to continue. Patients under our care were not allowed to continue in labour for more than 12 hours.

In the assessment of fetal anoxia during delivery we decided on three points of progress at which the $\mathrm{pH}$ could readily be compared. The first point, designated as sample 1, was taken as being the stage when the breech reached the perineumin other words, when it was possible to take a sample from either buttock or foot without the use of a speculum. The next definitive stage in the delivery is when the umbilicus reaches the introitus, and blood taken at this stage is designated as sample 2 . The final sample 3 was taken when the forceps had been applied to the after-coming head and immediately before the delivery of the mouth. It was, of course, realized that samples 2 and 3 were of no practical value so far as management was concerned, but in order to establish whether there was a relation between the 1-minute Apgar score and the final $\mathrm{pH}$ before delivery sample 3 was of vital importance. Latterly, intermediate samples were taken at 5 -minute intervals after sample 1 and were designated $1 \mathrm{a}, 1 \mathrm{~b}, 1 \mathrm{c}$, etc. until sample 2 was taken. It must be emphasized that a free flow of blood is essential for accuracy of the subsequent $\mathrm{pH}$ reading; whether the blood is taken from the buttock or foot appears to be immaterial. The technique of breech delivery involved the routine use of a pudendal block, the early disengagement of the legs, the Lovset manoeuvre to release the arms, and the application of forceps to the after-coming head. The sampling was done in the usual way with one minor modification in that small capillary tubes were used to collect the blood. The $\mathrm{pH}$ was read on a standard Astrup machine. A maternal venous sample was taken at each of the points 1,2 , and 3 . In our delivery suite the $\mathrm{pH}$ room was situated some 30 yards ( 35 metres) away from the delivery area, and a radio intercommunication system was used to pass on the $\mathrm{pH}$ finding at each stage. The obstetric team consisted of the two authors, a house officer, and a medical student.

\section{Results}

There had been 30 cases of breech presentation in the series at the time of writing. There were no cases of maternal or fetal mortality, and there had been no fetal morbidity of note. Caesarean section was carried out electively in two of the cases, and three patients underwent caesarean section during the first 
stage because of fetal distress. Twenty-five cases were monitored throughout the first and second stages of labour, and a summary of results is given in the Table.

Summary of Results of Monitoring throughout First and Second Stages of Labour in 25 Vaginal Deliveries

\begin{tabular}{|c|c|c|c|}
\hline & & rage Values & Average Values \\
\hline $\begin{array}{l}\text { Maturity (weeks) } \\
\text { pH-First stage } \\
\text { pH-Sample } 1 \ldots \\
\text { pH-Sample } 2 \ldots \\
\text { pH-Sample } 3 \ldots\end{array}$ & $\begin{array}{l}\ldots \\
\cdots \\
\cdots \\
\cdots\end{array}$ & $\begin{array}{l}38 \cdot 4 \\
7 \cdot 29 \\
7 \cdot 25 \\
7 \cdot 16 \\
7 \cdot 14\end{array}$ & $\begin{array}{lr}\text { (time taken in min) } & 4.3 \\
\text { Apgar score at } 1 \mathrm{~min} . & 4 \cdot 7 \\
\text { Apgar score at } 5 \mathrm{~min} . & 8 \cdot 4 \\
\text { Weight (g) } & 3,175 \\
\text { Duration of Labour (hours) } & 8.8\end{array}$ \\
\hline
\end{tabular}

A scattergram (Fig. 1) plots the Apgar score at one minute against the $\mathrm{pH}$ of sample 3 (sample taken immediately before delivery). A horizontal line has been drawn to separate those infants whose score at one minute was 4 or below from those whose score was 5 or above. The vertical line, drawn at what we regard as the critical $\mathrm{pH}$ level of $7 \cdot 15$, separates those infants whose $\mathrm{pH}$ immediately before birth was above or below this reading.

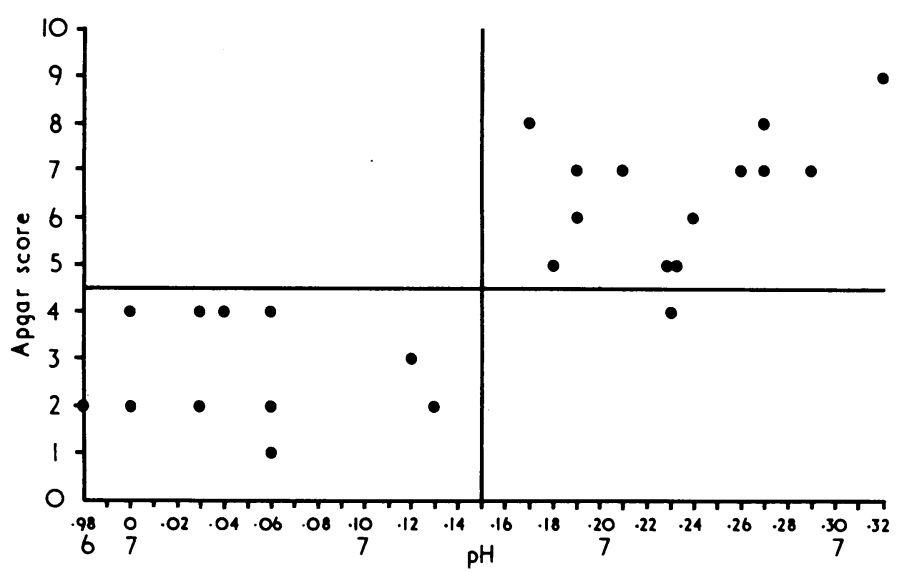

FIG. 1-Apgar score at one minute against fetal $\mathrm{pH}$ of sample 3.

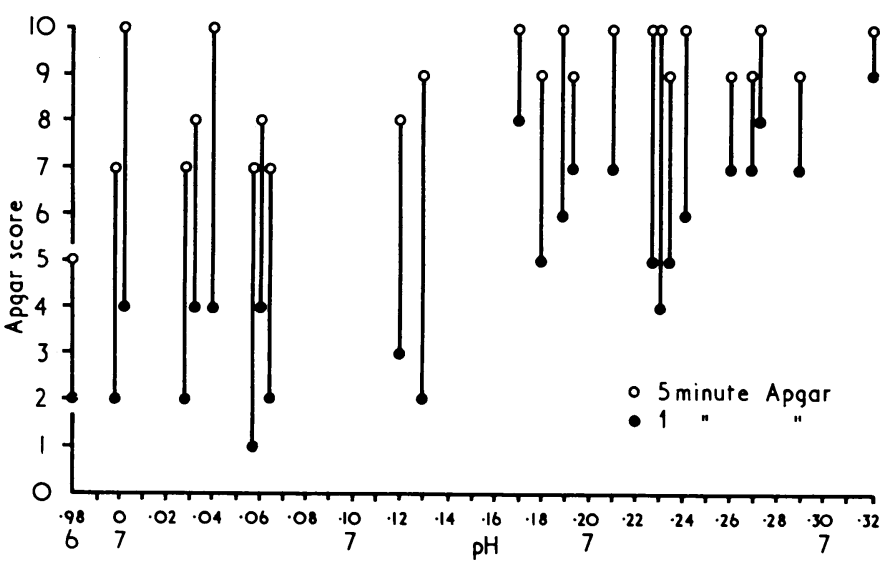

FIG. 2-Apgar score at one minute and five minutes against fetal $\mathrm{pH}$ of sample 3.

The Apgar score at one minute plotted against the $\mathrm{pH}$ of sample 3 and the corresponding five-minute score for each case is shown in Fig. 2.

The maternal $\mathrm{pH}$ was determined in all 25 cases at the specified points 1,2 , and 3 . The variation in successive maternal readings was so small that we thought that the influence on the fetal $\mathrm{pH}$ would be negligible.

\section{Discussion}

The only practical means of detecting fetal anoxia in the second stage of a breech labour is by the routine use of fetal blood sampling. An accurate $\mathrm{pH}$ value can be obtained within minutes of deciding that fetal blood sampling is indicated. This value reflects the actual acid-base status of the baby representing, as it were, the sum of all current influences on the $\mathrm{H}^{+}$ion concentration. As Saling (1966) has pointed out, for purely clinical purposes it is quite sufficient to confine oneself to blood $\mathrm{pH}$ measurements. Our management of breech deliveries has been based on this precept.

At the inception of this project, we expected to find that there was a continuous drop in the $\mathrm{pH}$ from the late first stage reading until delivery. It was also expected that the major fall would be at the time of supposed complete cord compression, from the time the umbilicus reaches the introitus until delivery of the head. Rather surprisingly our results did not corroborate these suppositions, and the average figures given in the Table show that there is in fact very little variation between the first stage reading and sample 1 . There is a sudden drop between sample 1 and sample 2, but there is very little further fall between sample 2 and sample 3 . We assume that the only explanation for this fall is cord compression, and that this may occur at any time after the breech has reached the perineum and not just from the time that the umbilicus has been delivered, as has commonly been supposed. In the present series we have noticed that this early fall in the $\mathrm{pH}$ has more often been found in the larger babies, and this may help to explain why smaller babies do so much better after breech delivery. Cox (1950) has shown that fetal mortality tends to rise as the birth weight increases, and we suggest that the increased size of these babies would lead to early cord compression and hence early anoxia which may be unrecognized. If this were so it could reasonably be supposed that cerebral bleeding of major or minor degree could take place in the presence of even minor trauma.

There is some diversity of opinion as to the correlation between fetal $\mathrm{pH}$ and the subsequent Apgar reading, but Lee (1972) suggested that there is a close relation. These figures, of course, refer to cephalic deliveries, and there is no reference in the literature to $\mathrm{pH}$ measurement of the baby delivered as a breech. Although our series at this stage is fairly small Fig. 1 shows that there is a clear correlation between the one-minute Apgar score and the $\mathrm{pH}$ of sample 3 . Of the twenty-five cases, 12 infants were found to have an Apgar score of 4 or below and 11 of these had a pH of less than 7-15. The remaining 13 cases, all of whom had a one-minute score of 5 or above, all had a $\mathrm{pH}$ at sample 3 above $7 \cdot 15$.

Fig. 2 shows that a one-minute score below 4 would tend to give a score of below 8 at five minutes. As we feel that the fiveminute Apgar score should be 9 or 10, and anything below this figure is cause for concern, management should be directed towards achieving a one-minute score of more than 4. Based on these observations we suggest that the $\mathrm{pH}$ be assessed at five-minute intervals from the time the breech reaches the perineum until the legs are disengaged in the case of an extended breech, or an equivalent stage in a flexed breech. If at any time the $\mathrm{pH}$ drops to a figure of $7 \cdot 15$ or below the baby should be delivered forthwith, if necessary by caesarean section. If, on the other hand, the $\mathrm{pH}$ remains above $7 \cdot 15$, and moreover if there is no pronounced fall during consecutive readings, this indicates that there is no serious cord compression and the delivery can be managed in the orthodox way. Thus the degree of oxygenation of the fetus can be continuously assessed during the second stage, as the fall in $\mathrm{pH}$ will usually occur before any alteration in the fetal heart rate.

\section{Conclusion}

Our method of breech management is based on the precept that cord compression is a variable factor and that it may occur at any time after the breech has reached the perineum. The degree of compression can only be assessed by $\mathrm{pH}$ sampling. In cases of severe anoxia, when the $\mathrm{pH}$ approaches the critical level of $7 \cdot 15$, there is usually ample warning of the fall provided the 
samples are taken at five-minute intervals, and serious trouble can be averted by expediting the delivery. This method of management has proved its value in two of our subsequent cases where a rapid fall in the $\mathrm{pH}$ to a figure below $7 \cdot 15$ was noted soon after the breech had reached the perineum. This indicated rapidly developing anoxia, so modified breech extraction was carried out forthwith, and in each case the baby was in excellent condition.

Significantly, these are the only babies who, despite having a pH of below 7.15, had a one-minute Apgar score of more than 4 and a five-minute score of more than 8 .

Having completed our pilot study, and analysed 13 subsequent cases, we have now evolved the following simple and practical form of management.

Group $A .-\mathrm{pH}$ below $7 \cdot 15$. Another sample is taken at once and if it is confirmed that the level is below 7.15 and immediate delivery is not possible, caesarean section is carried out.

Group B.-pH between $7 \cdot 20$ and $7 \cdot 15$. Five-minute sampling is carried out, but no action is taken unless the $\mathrm{pH}$ approaches $7 \cdot 15$, in which case the delivery is expedited by groin traction.

Group C.- $\mathrm{pH}$ above $7 \cdot 20$. If the five-minute samples remain above this figure no action is necessary and the baby is delivered in the usual manner.

We hope that by delivering a breech in good condition, and avoiding what has hitherto been regarded as harmless asphyxia, that we can obviate the risk of minor degrees of brain damage. Unfortunately, the effects of brain damage are not immediately obvious, but may well manifest themselves in later years. With this in mind we intend to follow up the infants delivered in this series, and we are at present carrying out a follow-up of 250 cases of breech delivery conducted by one of us (J.G.H.) between 1964 and 1966.

We would like to thank the South East Metropolitan Regional Hospital Board for the financial assistance for this research project. We would also like to thank Mr. B. G. Pickles for his enthusiastic co-operation, and we are grateful to the medical staff, both obstetric and paediatric, to the midwives, research assistants, and secretarial staff who have all given such valuable support. We are also indebted to Mr. C. K. Vartan for his valuable advice and encouragement.

\section{References}

Chassar Moir, J., and Myerscough, P. R. (1971). Operative Obstetrics, 8th edn. London, Baillière.

Cox, L. W. (1950). Fournal of Obstetrics and Gynaecology of the British Empire, $51,197$. Dieckmann, W. J. (1946). American fournal of Obstetrics and Gynecology, 52, Donald, I. (1969a). Practical Obstetric Problems, 4th edn., p. 337. London,
Lloyd Luke. Donald, I. (1969b). Practical Obstetric Problems, 4th edn., p. 624. London,

Holland, E. (1920). Transcripts of the Edinburgh Obstetric Society, 40, 112.

Gibberd, G. F. (1931). British Medical fournal, 2, 369

Gibberd, G. F. (1955). Short Textbook of Midwifery, 6th edn. London, Churchill.

Hay, D. (1959). Fournal of Obstetrics and Gynaecology of the British Empire, 66, 529.

Lee, K. H. (1972). Postgraduate Medical fournal, 48, 405.

Payling Wright, G. (1960). Introduction to Pathology, 3rd edn., p. 402. London, Longmans Green.

Saling, E. (1966). Foetal and Neonatal Hypoxia, p. 101. London, Arnold.

Tompkins, P. (1943). American fournal of Obstetrics and Gynecology, 46, 695.

Vartan, C. K. (1945). Fournal of Obstetrics and Gynaecology of the British Empire, 52, 417 .

\title{
Cutaneous Sarcoidosis in Blood Donation Venepuncture Sites
}

\author{
B. W. HANCOCK
}

British Medical fournal, 1972, 4, 706-708

\section{Summary}

Six patients were studied in whom sarcoidosis first showed itself by the development of granulomata at the site of previous venepunctures. The diagnosis was histologically confirmed in all cases. The treatment of the lesions with triamcinolone did not seem to hasten resolution.

\section{Introduction}

The infiltration of old and new cutaneous scars by granulomatous tissue in sarcoidosis is well recognized. Six of 200 patients (James, 1959) and 11 of 275 patients (Scadding, 1967) had infiltration of scars by sarcoid tissue, and this was the most common form of skin sarcoidosis reported from Stockholm (Löfgren and Stavenow, 1961). The scars were usually posttraumatic or postoperative or, occasionally, after inoculations.

Six cases of sarcoid granuloma, all presenting in blood donation venepuncture scars, seemed such a curiously high incidence of a rare presentation that it was regarded as worthy of a report.

\footnotetext{
Rupert Hallam Dermatology Department, Hallamshire Hospital, Sheffield

B. W. HANCOCK, M.B., D.C.H., Senior House Officer
}

\section{Patients}

The histories and findings of the six cases are summarized in Tables I and II.

Of the six patients five were women, and the age of presentation varied from 28 to 53 years. All the patients had received venepunctures when donating blood, in Case 1 as many as 34 donations over 20 years and in Case 3 only one donation four years previously. The period that had elapsed between the last venesection and the first appearance of cubital fossa lesions varied from three days to seven years. The cubital fossa lesions were the only and presenting cutaneous manifestation of sarcoidosis in four patients and in Case 2 were the only manifestation of the disease (Figs. 1-4).

The general health of all patients was good though five showed bilateral hilar lymphadenopathy on chest radiography, but only one of these (Case 5) had any evidence of lung parenchymal involvement, and this without impairment of pulmonary function.

Histology of cubital fossa lesions in all cases showed granuloma formation with epithelioid cells, giant cells, and lymphocytes without evidence of caseation or acid fast bacilli or foreign bodies. Mantoux tests (1/1,000 solution) on five patients were all negative after 48 hours, and the highest erythrocyte sedimentation rate (Westergren) recorded was 16 millimetres in one hour.

In the four earlier cases, three with bilateral hilar lymphadenopathy (Cases 1, 3, and 4), all skin lesions had resolved within 15 months of presentation and, though in Case 1 there was minimal hilar lymphadenopathy at the time of discharge from 